\title{
Model of antral follicle dynamics during the 5-day cycle in rats based on measurement of antral follicle inflow
}

\author{
W. A. van Cappellen, P. Osman and H. M. A. Meijs-Roelofs \\ Department of Endocrinology and Reproduction, Medical Faculty, Erasmus University, Rotterdam, \\ PO Box 1738, 3000 DR Rotterdam, The Netherlands
}

\begin{abstract}
Antral follicles were counted in ovaries from young adult Wistar rats, collected on the 5 days of the ovarian cycle. Follicles were classified as healthy, early atretic or late atretic and divided into five volume classes. From these data, a model was developed in which the inflow of healthy follicles into the various size classes was quantified. This model describes the follicle dynamics during a normal 5-day cycle. It was concluded that the stage of early atresia takes between 20 and $24 \mathrm{~h}$. The inflow of follicles into the antral stage (volume $\geq 100 \times 10^{5} \mu^{3}$ ) was continuous but not constant. The highest inflow was found during pro-oestrus and oestrus, at about the time of the first and second FSH surge. The total inflow during each cycle was about 120 follicles of which only $10 \%$ ovulated. These ovulating follicles were recruited during the previous pro-oestrus and oestrus. Follicle selection took place in volume classes 1 and 2 (volume $100-350 \times 10^{5} \mu \mathrm{m}^{3}$ ) during oestrus and dioestrus 1 . At dioestrus 2, the follicles that will ovulate have been selected and can be recognized on the basis of their bigger size.
\end{abstract}

\section{Introduction}

Recent developments in in situ hybridization and immunohistochemical techniques make it possible to study the regulation of a large number of endocrine and paracrine factors in the ovary. It is important to have a model of follicle dynamics during the ovarian cycle so that the results obtained with these new techniques can be interpreted correctly. It is not known, for instance, whether growing follicles continuously enter the antral follicle stage throughout the cycle (Peters and Levy, 1966; Pedersen, 1970; Hirshfield and DePaola, 1981; Hirshfield, 1988) or whether there is a resting pool of preantral follicles from which follicles are recruited only during oestrus (Greenwald, 1973, 1974; Osman, 1985). This question is particularly important in relation to treatments aiming at increasing the number of ovulatory follicles. For a basic understanding of ovulatory quota reached at superovulation it is of interest to know the total number of follicles involved in cyclic follicle development. Moreover, knowing the developmental path of the follicles destined to ovulate may be of great help in interpreting results of histological and in vitro studies. In this study a model will be developed in which the inflow of antral follicles is quantified. This model should provide a tool to discriminate between the effect of increased/decreased follicle inflow and decreased/ increased atresia in in vivo experiments. The model, although derived from static data, presents a dynamic picture of antral follicle development. In this study we also try to fit isolated statements about follicle dynamics, found in the literature, into one model.

\section{Materials and Methods}

The histological material previously used and the follicle counts made earlier (Osman, 1985) served as a basis for the development of a model of inflow into the antral follicle stages.

Adult female rats of our inbred Wistar substrain (RAmsterdam) were used and kept in a controlled temperature $\left(22-25^{\circ} \mathrm{C}\right)$ with lights on from 05.00 to $19.00 \mathrm{~h}$. Standard dry pellets and tap water were available ad libitum. Vaginal smears were taken daily at $10.00 \mathrm{~h}$. The first day after oestrus when an influx of leucocytes became visible in the vaginal smears was designated as dioestrus 1 . Only animals displaying at least two consecutive 5-day cycles were used.

Groups of 6-7 animals were killed on each day of the cycle, at $10.00 \mathrm{~h}$ and $17.00 \mathrm{~h}$ with an overdose of ether. The ovaries were dissected out, fixed in Bouin's fluid and embedded in paraffin wax. Serial sections of $10 \mu \mathrm{m}$ were stained with haematoxylin and eosin.

The number of follicles was counted in one ovary per animal. All follicles with a volume $\geq 100 \times 10^{5} \mu^{3}$ (diameter $\geq 265 \mu \mathrm{m}$ ) were measured in the section containing the nucleolus of the oocyte to ensure that all follicles were measured only once. These follicles were all at the antral stage of development. Follicles were divided in 5 volume classes: class $1,100-200 \times$ $10^{5} \mu^{3}$ diameter $\left.265-350 \mu \mathrm{m}\right)$; class $2,200-350 \times 10^{5} \mu \mathrm{m}^{3}$ (diameter 350-400 $\mu \mathrm{m}$ ); class 3, 350-500 $\times 10^{5} \mu \mathrm{m}^{3}$ (diameter $400-450 \mu \mathrm{m}$ ); class $4,500-1000 \times 10^{5} \mu^{3}$ (diameter $450-$ $575 \mu \mathrm{m}$ ) and class $5 \geq 1000 \times 10^{5} \mu \mathrm{m}^{3}$ (diameter $\geq 575 \mu \mathrm{m}$ ). All follicles were classified as healthy, early atretic or late atretic. A follicle was regarded as early atretic when there was at least localized pycnosis in the granulosa cell layer, but the nucleolus 
Table 1. Number of healthy, (early atretic) and [late atretic] follicles in one ovary at $10 \mathrm{~h}$ in the morning of the various days of the ovarian cycle of rats

\begin{tabular}{lccccc}
\hline $\begin{array}{l}\text { Volume class } \\
\left(\times 10^{5} \mu \mathrm{m}^{3}\right)\end{array}$ & Oestrus & Dioestrus 1 & Dioestrus 2 & Dioestrus 3 & Pro-oestrus \\
\hline 5 & 0.0 & 0.0 & 0.0 & $3.5 \pm 0.9$ & $5.6 \pm 0.8$ \\
$(\geq 1000)$ & $(0.5 \pm 0.3)$ & $(0.0)$ & $(0.0)$ & $(0.3 \pm 0.2)$ & $(0.3 \pm 0.2)$ \\
& {$[0.2 \pm 0.2]$} & {$[0.0]$} & {$[0.0]$} & {$[0.0]$} & {$[0.0]$} \\
4 & 0.0 & $1.3 \pm 0.6$ & $5.7 \pm 1.0$ & $3.2 \pm 0.8$ & $0.3 \pm 0.2$ \\
$(500-1000)$ & $(0.5 \pm 0.3)$ & $(0.2 \pm 0.2)$ & $(0.2 \pm 0.2)$ & $(1.3 \pm 0.3)$ & $(1.0 \pm 0.4)$ \\
& {$[0.0]$} & {$[0.0]$} & {$[0.2 \pm 0.2]$} & {$[0.0]$} & {$[0.3 \pm 0.2]$} \\
3 & $0.3 \pm 0.2$ & $4.3 \pm 0.7$ & $3.2 \pm 1.1$ & 0.0 & 0.0 \\
$(350-500)$ & $(0.0)$ & $(0.7 \pm 0.3)$ & $(1.8 \pm 0.8)$ & $(1.5 \pm 0.3)$ & $(0.0)$ \\
& {$[0.3 \pm 0.2]$} & {$[0.0]$} & {$[0.2 \pm 0.2]$} & {$[0.3 \pm 0.2]$} & {$[0.9 \pm 0.3]$} \\
2 & $8.3 \pm 0.7$ & $14.7 \pm 0.7$ & $5.8 \pm 1.4$ & $0.3 \pm 0.2$ & $0.3 \pm 0.2$ \\
$(200-350)$ & $(1.5 \pm 1.0)$ & $(5.0 \pm 1.3)$ & $(5.5 \pm 0.7)$ & $(5.2 \pm 0.9)$ & $(1.3 \pm 0.4)$ \\
& {$[2.8 \pm 0.9]$} & {$[0.2 \pm 0.2]$} & {$[3.3 \pm 1.1]$} & {$[3.3 \pm 0.9]$} & {$[3.0 \pm 1.0]$} \\
1 & $19.7 \pm 1.5$ & $11.3 \pm 1.9$ & $9.3 \pm 1.3$ & $5.8 \pm 0.8$ & $8.4 \pm 1.6$ \\
$(100-200)$ & $(2.3 \pm 0.9)$ & $(6.3 \pm 1.8)$ & $(5.2 \pm 0.6)$ & $(7.8 \pm 1.2)$ & $(6.1 \pm 2.1)$ \\
& {$[11.2 \pm 1.0]$} & {$[2.7 \pm 1.0]$} & {$[8.3 \pm 1.6]$} & {$[12.0 \pm 1.6]$} & {$[9.4 \pm 1.8]$} \\
Number of rats & 6 & 6 & 6 & 6 & 7 \\
\hline
\end{tabular}

Values are means \pm SEM.

was still visible. Late atresia was defined by the presence of pycnosis all over the granulosa cell wall and changes of the oocyte such as breakdown of the nuclear membrane with or without formation of a maturation spindle, and oocyte fragmentation.

\section{Results}

During the cycle a daily change was found in the number of antral follicles in the different volume classes of healthy follicles (Table 1). Class 1 follicles were present throughout the cycle and reached highest numbers at oestrus and lowest numbers at dioestrus 3. Large numbers of class 2 follicles were present at oestrus, dioestrus 1 and dioestrus 2 . At dioestrus 3 and prooestrus there were few class 2 follicles. Class 3 follicles were nearly exclusively present at dioestrus 1 and 2 and class 4 follicles at dioestrus 1,2 and 3. Class 5 follicles were seen only at the end of the cycle (dioestrus 3 and pro-oestrus).

Early atresia was infrequent in all volume classes (but not always lowest) at oestrus and tended to increase to maximum values during dioestrus (Table 1). Late atresia did not show much variation except for the low total number at dioestrus 1 . Late atresia on all days is highest in volume class 1 (Table 1 ).

During the cycle, follicles are growing through the different follicle classes and finally ovulate or become atretic. By counting the number of follicles in histological sections the number of healthy follicles at $10.00 \mathrm{~h}$ and $17.00 \mathrm{~h}$ was known. To calculate the inflow of follicles from one class into the other, it is necessary to know how many follicles left a healthy follicle class by early atresia between two time points. For this it is necessary to know how long a follicle stays at the stage of early atresia as well as the number of early atretic follicles at a time point. From the follicle counts an indication of the duration of early atresia could be found. The rise in the number of early atretic follicles between oestrus and dioestrus 1 (from $4.8 \pm 1.6$ to $12.2 \pm 1.7$, Table 1 ) is followed $24 \mathrm{~h}$ later by a rise in the number of late atretic follicles (from $2.8 \pm 0.9$ to $12.0 \pm 1.8$, Table 1 ), indicating that early atresia takes about $24 \mathrm{~h}$.

This value of $24 \mathrm{~h}$ was used to construct a first model in which the inflow of follicles was calculated. Only the numbers of follicles counted in the rats at $10.00 \mathrm{~h}$ were used.

On dioestrus 2, no class 5 follicles were seen. On dioestrus 3 , 3.5 healthy and 0.3 early atretic follicles were counted: $3.5+$ $0.3=3.8$ follicles must therefore have entered volume class 5 between dioestrus 2 and dioestrus 3. At pro-oestrus, 5.6 healthy and 0.3 early atretic class 5 follicles were counted. The 0.3 early atretic follicles differed from the 0.3 early atretic follicles of dioestrus 3: $5.6+0.3-3.5$ (3.5 follicles were already present the day before) $=2.4$ follicles must therefore have entered class 5 over the past $24 \mathrm{~h}$.

In the same way the number of follicles that entered class 4 from oestrus to dioestrus 1 and from dioestrus 1 to dioestrus 2 could be calculated (Fig. 1) using the formula:

Inflow $=$ number of healthy follicles + number of early atretic follicles - number of healthy follicles present on previous day

Between dioestrus 2 and dioestrus 3 healthy follicles leave class 4 by atresia as well as by growing, that is developing into the bigger follicles of class 5 . The formula has to be changed to:

Infow $=$ number of healthy follicles + number of early atretic follicles + inflow to bigger size class - number of healthy follicles present on previous day

In this way the inflow into class 4 between dioestrus 2 and dioestrus 3 could be calculated as $3.2+1.3+3.8-5.7=$ 2.6. Repeating this calculation, inflow values for the five volume classes could be calculated throughout the cycle (Fig. 1).

The sum of all follicles entering class $I$ during the 5 days of the cycle represents the number of follicles involved in antral 
Table 2. Inflow of follicles from one follicle class to another during the 5-day cycle of the rat. Models were calculated separately for the rats killed at 10 and at $17 \mathrm{~h}$

\begin{tabular}{|c|c|c|c|c|c|c|c|c|c|c|c|c|c|c|}
\hline \multirow{2}{*}{$\begin{array}{l}\text { Follicle } \\
\text { volume } \\
\text { class }\end{array}$} & \multirow[b]{2}{*}{ Factor ${ }^{a}$} & \multirow[b]{2}{*}{$\begin{array}{c}\operatorname{Time}^{\mathrm{b}} \\
\text { (h) }\end{array}$} & \multicolumn{6}{|c|}{ Inflow of follicles in $24 \mathrm{~h}$ of rats killed at $10 \mathrm{~h}$} & \multicolumn{6}{|c|}{ Inflow of follicles in $24 \mathrm{~h}$ of rats killed at $17 \mathrm{~h}$} \\
\hline & & & $\mathrm{OE}$ & D1 & D2 & D3 & $\mathrm{PO}$ & $\begin{array}{c}\text { Inflow } \\
\text { total }\end{array}$ & $\mathrm{OE}$ & D1 & $\mathrm{D} 2$ & D3 & PO & $\begin{array}{c}\text { Inflow } \\
\text { total }\end{array}$ \\
\hline 5 & 0.2 & 120 & & 0.0 & 0.0 & 3.6 & 2.2 & 10.8 & & 0.0 & 0.2 & 3.2 & 1.1 & 4.5 \\
\hline 4 & 0.2 & 120 & -0.2 & 1.3 & 4.4 & 1.4 & -0.5 & 6.4 & 0.0 & 1.1 & 3.9 & 0.6 & -0.4 & 5.2 \\
\hline 3 & 0.2 & 120 & 0.1 & 5.4 & 3.7 & -1.5 & -0.5 & 7.2 & 1.2 & 5.2 & 2.1 & -1.6 & -0.6 & 6.3 \\
\hline 2 & 0.2 & 120 & 8.4 & 12.8 & -4.1 & -6.0 & -0.2 & 10.9 & 14.3 & 5.7 & -5.7 & -3.2 & -0.9 & 10.2 \\
\hline 1 & 0.2 & 120 & 20.2 & 5.7 & -5.1 & -7.9 & 3.6 & 16.5 & 26.7 & -1.1 & -7.5 & -1.7 & 0.3 & 16.7 \\
\hline 5 & 0.5 & 48 & & 0.0 & 0.0 & 3.7 & 2.2 & 10.9 & & 0.0 & 0.2 & 3.2 & 1.1 & 4.5 \\
\hline 4 & 0.5 & 48 & 0.0 & 1.4 & 4.5 & 1.9 & -0.2 & 7.6 & 0.1 & 1.1 & 3.9 & 0.9 & -0.3 & 5.7 \\
\hline 3 & 0.5 & 48 & 0.3 & 5.7 & 4.3 & -0.5 & -0.2 & 9.6 & 1.3 & 5.4 & 2.6 & -1.0 & -0.4 & 7.9 \\
\hline 2 & 0.5 & 48 & 9.1 & 14.6 & -1.8 & -3.4 & 0.4 & 18.9 & 14.5 & 7.0 & -4.2 & -1.1 & -0.4 & 15.8 \\
\hline I & 0.5 & 48 & 21.6 & 9.4 & -1.2 & -3.0 & 6.1 & 32.9 & 27.2 & 1.7 & -5.0 & 2.0 & 2.7 & 28.6 \\
\hline 5 & 0.67 & 36 & & 0.0 & 0.0 & 3.7 & 2.3 & 11.0 & & 0.0 & 0.2 & 3.2 & 1.1 & 4.5 \\
\hline 4 & 0.67 & 36 & 0.0 & 1.4 & 4.5 & 2.1 & 0.1 & 8.1 & 0.2 & 1.1 & 3.9 & 1.2 & -0.2 & 6.2 \\
\hline 3 & 0.67 & 36 & 0.3 & 5.8 & 4.6 & -0.1 & 0.1 & 10.7 & 1.4 & 5.4 & 3.0 & -0.4 & -0.2 & 9.2 \\
\hline 2 & 0.67 & 36 & 9.3 & 15.6 & -0.6 & -2.1 & 1.0 & 23.2 & 14.7 & 7.7 & -3.1 & 0.4 & 0.0 & 19.7 \\
\hline 1 & 0.67 & 36 & 22.2 & 11.4 & 0.9 & -0.4 & 7.7 & 41.8 & 27.6 & 3.4 & -3.2 & 4.5 & 4.4 & 36.7 \\
\hline 5 & 1 & 24 & & 0.0 & 0.0 & 3.8 & 2.4 & 11.2 & & 0.0 & 0.2 & 3.2 & 1.2 & 4.6 \\
\hline 4 & 1 & 24 & 0.2 & 1.5 & 4.6 & 2.6 & 0.5 & 9.4 & 0.4 & 1.1 & 3.9 & 1.6 & 0.0 & 7.0 \\
\hline 3 & 1 & 24 & 0.5 & 6.2 & 5.3 & 0.9 & 0.5 & 13.4 & 1.6 & 5.6 & 3.7 & 0.4 & 0.1 & 11.4 \\
\hline 2 & 1 & 24 & 10.0 & 17.6 & 1.9 & 0.6 & 1.8 & 31.9 & 15.0 & 9.3 & -1.1 & 3.1 & 0.7 & 27.0 \\
\hline 1 & 1 & 24 & 23.6 & 15.5 & 5.1 & 4.9 & 10.5 & 59.6 & 28.4 & 7.0 & 0.2 & 9.2 & 7.7 & 52.5 \\
\hline 5 & 1.2 & 20 & & 0.0 & 0.0 & 3.9 & 2.4 & 11.3 & & 0.0 & 0.2 & 3.2 & 1.2 & 4.6 \\
\hline 4 & 1.2 & 20 & 0.3 & 1.5 & 4.6 & 3.0 & 0.7 & 10.1 & 0.5 & 1.1 & 3.9 & 1.9 & 0.1 & 7.5 \\
\hline 3 & 1.2 & 20 & 0.6 & 6.3 & 5.7 & 1.6 & 0.7 & 14.9 & 1.7 & 5.7 & 4.1 & 0.9 & 0.3 & 12.7 \\
\hline 2 & 1.2 & 20 & 10.4 & 18.7 & 3.4 & 2.3 & 2.2 & 37.0 & 15.2 & 10.3 & 0.1 & 4.8 & 1.1 & 31.5 \\
\hline 1 & 1.2 & 20 & 24.5 & 17.9 & 7.6 & 8.2 & 12.2 & 70.4 & 28.9 & 9.2 & 2.2 & 12.2 & 9.7 & 62.2 \\
\hline 5 & 1.5 & 16 & & 0.0 & 0.0 & 4.0 & 2.5 & 11.5 & & 0.0 & 0.2 & 3.2 & 1.3 & 4.7 \\
\hline 4 & 1.5 & 16 & 0.5 & 1.6 & 4.7 & 3.5 & 1.1 & 11.4 & 0.7 & 1.1 & 3.9 & 2.3 & 0.3 & 8.3 \\
\hline 3 & 1.5 & 16 & 0.8 & 6.6 & 6.4 & 2.6 & 1.1 & 17.5 & 1.9 & 5.9 & 4.8 & 1.7 & 0.6 & 14.9 \\
\hline 2 & 1.5 & 16 & 11.1 & 20.5 & 5.8 & 4.9 & 3.0 & 45.3 & 15.5 & 11.8 & 2.0 & 7.3 & 1.8 & 38.4 \\
\hline 1 & 1.5 & 16 & 25.9 & 21.6 & 11.5 & 13.1 & 14.8 & 86.9 & 29.6 & 12.5 & 5.4 & 16.5 & 12.7 & 76.7 \\
\hline
\end{tabular}

${ }^{2}$ Factor to multiply the number of early atretic follicles by to simulate an early atretic stage which takes more (factor $<1$ ) or less (factor $>1$ ) than $24 \mathrm{~h}$.

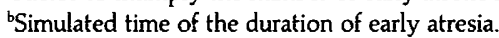

OE: oestrus; D1: dioestrus 1; D2: dioestrus 2; D3: dioestrus 3; PO: pro-oestrus.

follicle dynamics leading towards ovulation during that cycle. This sum amounts to $59.6(15.5+5.1+4.9+10.5+23.6)$ follicles per ovary (Fig. 1). During one cycle in the rat strain used about 120 follicles, therefore, grow into the antral follicle classes $\geq 100 \times 10^{5} \mu \mathrm{m}^{3}$ per two ovaries. Only about $10 \%$ of this number will ovulate.

There was a continuous inflow of follicles into class 1 (that of the smallest antral) follicles, but not at a constant rate. The inflow from pro-oestrus at $10.00 \mathrm{~h}$ to oestrus at $10.00 \mathrm{~h}$ is very high ( 23.6 follicles in $24 \mathrm{~h}$ ) and this inflow remains high between oestrus at $10.00 \mathrm{~h}$ and dioestrus $\mathrm{I}$ at $10.00 \mathrm{~h}(15.5$ follicles in $24 \mathrm{~h}$ ). Thus during the periovulatory period, the time of the first and secondary FSH peak, inflow was highest.

With the model (Fig. 1) it was possible to track down the path of follicles that ovulate. Follicles that eventually ovulate (class 5 follicles) have entered class 5 during dioestrus 3 and pro-oestrus or, referring to the procedure of follicle counting, between dioestrus 2 at $10.00 \mathrm{~h}$ and pro-oestrus at $10.00 \mathrm{~h}$.
These follicles were class 4 follicles during dioestrus 2 and dioestrus 3, class 3 follicles during dioestrus 1 and dioestrus 2 , class 2 follicles during oestrus and dioestrus $I$ and class $I$ follicles during oestrus and pro-oestrus of the preceding cycle. Thus we could trace the time-track of the follicles destined to ovulate, including the moment of their recruitment (i.e. inflow into the antral class 1 ) which was during pro-oestrus and oestrus and the moment they were selected (i.e. selection to continued growth up to ovulatory size instead of becoming atretic) which was during the days of oestrus and dioestrus 1 .

The model was also developed from the follicle counts made in a group of rats killed at $17.00 \mathrm{~h}$ (Fig. 2). Follicle dynamics did not show much difference compared with those of the group of rats killed at $10.00 \mathrm{~h}$ (Fig. 1).

Once the type and number of follicles from which the ovulating follicles would emerge were known for every day of the cycle, it seemed of equal interest to characterize follicles which will become atretic. In an attempt to achieve this, follicles were 
$\begin{array}{llllll}\text { Oestrus } & \text { D1 } & \text { D2 } & \text { D3 } & \text { PO } & \text { OE }\end{array}$

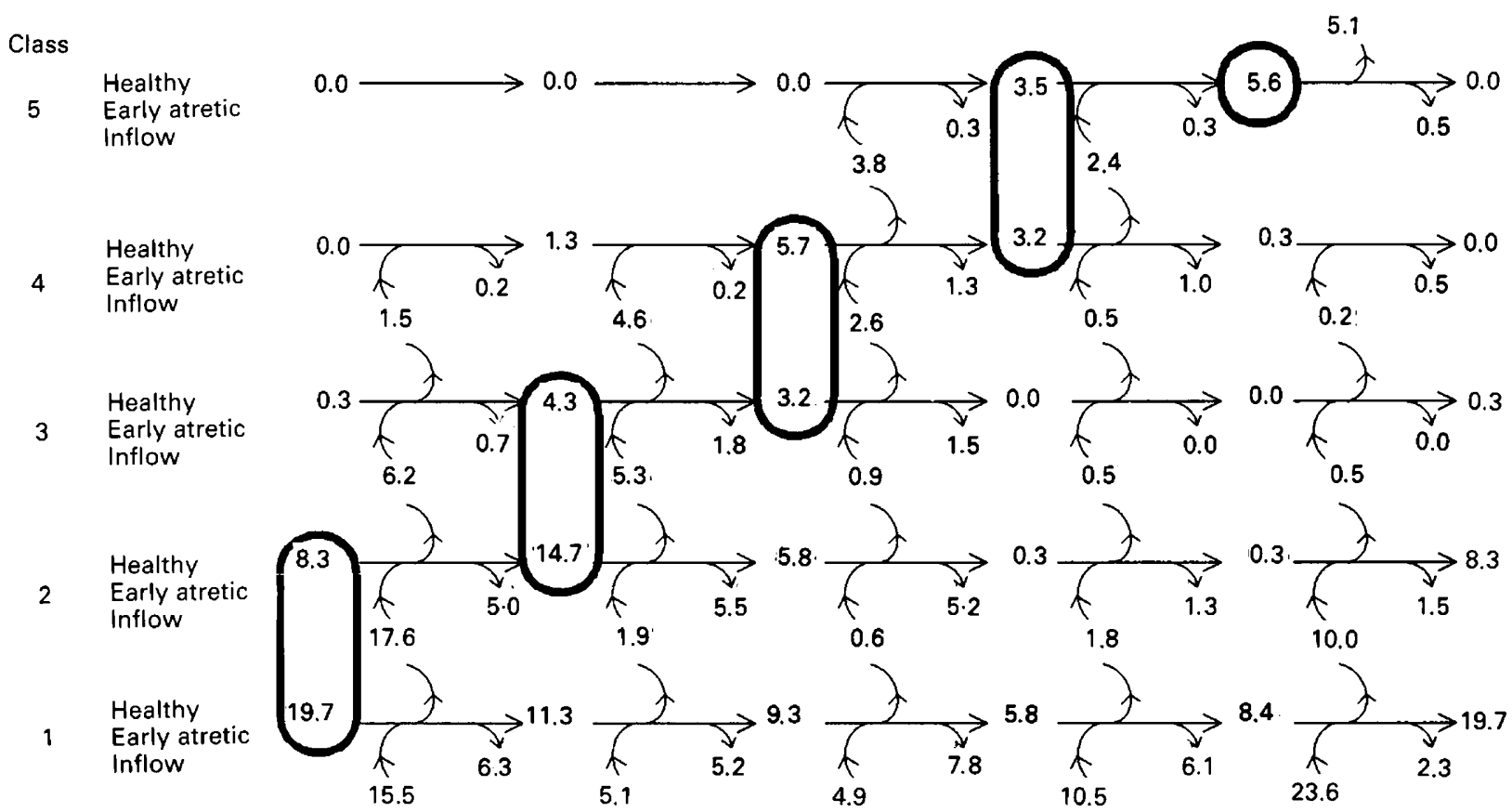

Fig. 1. Inflow of antral follicles in one ovary into the different volume classes during the cycle of rats. Upward arrow: number of follicles entering a class (inflow). Downward arrow: number of early atretic follicles. Numbers of healthy and atretic follicles were counted at $10.00 \mathrm{~h}$ in the morning. The inflow data are based on an early atretic period of $24 \mathrm{~h}$. Numbers surrounded by an ovoid indicate the type of follicle containing those that will ovulate at pro-oestrus. OE: oestrus; D1: dioestrus 1, D2: dioestrus 2, D3: dioestrus 3, PO: pro-oestrus.
Oestrus
D1
D2
D3
PO
OE

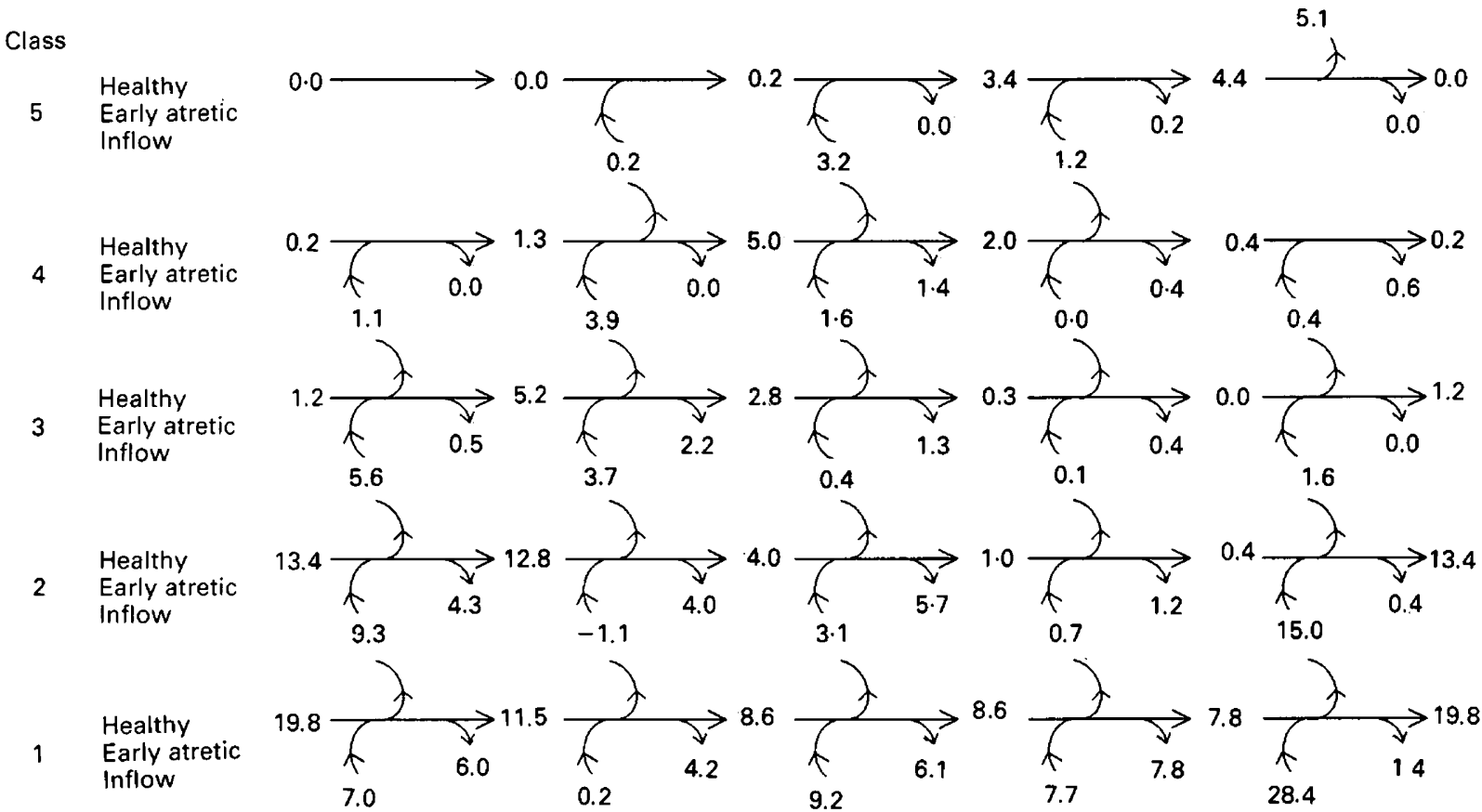

Fig. 2. Inflow of antral follicles in one ovary into the different volume classes during the cycle of rats. Upward arrow: number of follicles entering a class (inflow). Downward arrow: number of early atretic follicles. Numbers of healthy and atretic follicles were counted at $17.00 \mathrm{~h}$. The stage of early atresia was assumed to take $24 \mathrm{~h}$. OE: oestrus; D1: dioestrus 1; D2: dioestrus 2; D3: dioestrus 3; PO: pro-oestrus. 

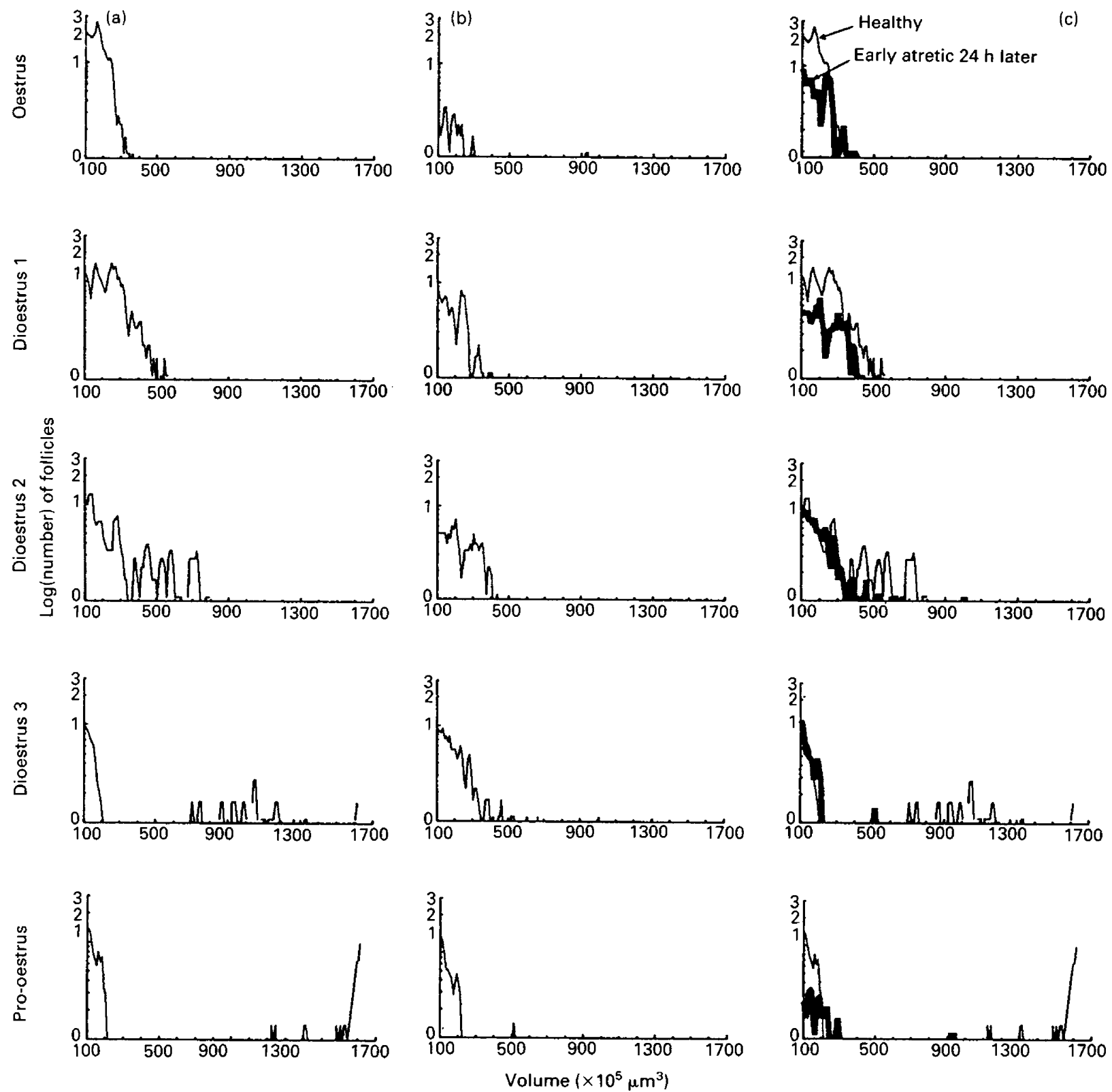

Fig. 3. Profiles of (a) healthy and (b) early atretic follicles in one ovary at $10.00 \mathrm{~h}$ during the various days of the cycle; (c) represents the number of healthy follicles (thin line) with the number of early atretic follicles (thick line) $24 \mathrm{~h}$ later projected on top of it. For instance the top right panel displays the number of healthy follicles at oestrus (thin line) and the number of early atretic follicles at dioestrus 1 (thick line). Follicles are classified in $15 \mathrm{I}$ classes with a width of $10 \times 10^{5} \mu \mathrm{m}^{3}$. The values were smoothed with a moving average of three values. Class 151 contains all follicles with a volume $>1600 \times 10^{5} \mu \mathrm{m}^{3}$. The $y$-axis is logarithmic in all graphs.

divided into much smaller classes of equal width $(10 \times$ $10^{5} \mu \mathrm{m}^{3}$ ) ranging from 100 to $1600 \times 10^{5} \mu \mathrm{m}^{3}$. The results of this classification, after smoothing with a moving average of three values, are shown (Fig. 3). The right five panels show for each day of the cycle the number of healthy follicles in combination with the number of early atretic follicles $24 \mathrm{~h}$ later (Fig. $3 c$ ). This was done to show which part of, for instance, the healthy follicle population of oestrus at $10.00 \mathrm{~h}$ will be early atretic at dioestrus 1 at $10.00 \mathrm{~h}$. Thus the early atretic follicles of dioestrus 1 at $10.00 \mathrm{~h}$ are projected on top (thick line) of the healthy follicles of oestrus $10.00 \mathrm{~h}$ (Fig. 3a top panel).
From the group of healthy follicles present at oestrus, only a small part will become atretic within $24 \mathrm{~h}$ (Fig. 3c, note that the $y$-axis is logarithmic). On dioestrus 1 more of the follicles with a volume between 100 and $350 \times 10^{5} \mu^{3}$ (class 1 and 2) will become atretic. At dioestrus 2, almost all follicles $<350 \times$ $10^{5} \mu \mathrm{m}^{3}$ will become atretic. This means that the larger follicles present at dioestrus 2 did grow into the larger size classes and were finally selected to ovulate. An interesting phenomenon was seen at dioestrus 3 , when a clear gap between the smaller (up to $350 \times 10^{5} \mu \mathrm{m}^{3}$ ) antral and the larger (above $700 \times$ $10^{5} \mu^{3}$ ) follicles appears. This gap was still present at pro- 
oestrus. The smallest antral follicles $\left(<350 \times 10^{5} \mu \mathrm{m}^{3}\right.$, Fig. $\left.3 \mathrm{c}\right)$ present at pro-oestrus will no longer become atretic and they will be joined by the high inflow into class 2 follicles during the next 2 days.

\section{Discussion}

The model of follicle inflow developed here was based on the assumption that the passage of follicles through the early stages of atresia takes about $24 \mathrm{~h}$. Moreover, no correction was made for shrinkage of atretic follicles that might lead to disappearance of follicles into smaller volume classes. This latter point will be discussed first. Because in different studies criteria for atresia have been used, it is difficult to compare the reported or implied speed of shrinkage of atretic follicles. Byskov (1974) in an electron microscope study in mice described atresia as a process lasting 3-4 days, ending in follicles reaching the collapsed luteinized state. This state is comparable to the late atretic $2^{b}$ phase according to Osman (1985), which is reached in rats more than $48 \mathrm{~h}$ after the start of atresia. Considering the normal shape of early atretic follicles and the fact that there are early atretic follicles in all volume classes in which healthy follicles are found, it is likely that follicle shrinkage only takes place at a very low rate in early atretic follicles. Probably, late atretic follicles will shrink much faster as shown in this study in which almost no large (class 3, 4 and 5) late atretic follicles are seen, although large early atretic follicles were counted. Because the rate of shrinkage of early atretic follicles is not known (but is probably low, as discussed above) an alternative model was made in which a correction was made for follicle shrinkage. It was assumed that $30 \%$ of the early atretic follicles in a volume class had shrunk to a volume of the previous (smaller) volume size class. This was corrected for by increasing the number of early atretic class 5 follicles by $30 \%$. The number of early atretic follicles of class 4 , left after reduction of the $30 \%$ of class 5 , was then increased by $30 \%$. The same procedure was applied for the number of the early atretic volume classes 3,2 and 1. This correction cannot be made for pro-oestrus and oestrus class 4 early atretic follicles because there are no class 3 early atretic follicles. In this case there was no increase in the number of early atretic class 4 follicles.

Use of the thus corrected model presented here resulted in only minor changes in follicle inflow. Thus the possible shrinkage of early atretic follicles does not seem to have much influence on the model. For the same reason, growth of early atretic follicles, which is not very likely because of the low mitotic index of early atretic follicles (Hirshfield, 1989), does not have much influence on the model. Reversal of early atresia does influence the model, but Hirshfield (1989) concluded that there is no return to the ovulatory pathway after follicles become atretic.

With regard to the assumption that early atresia takes $24 \mathrm{~h}$, the following points can be raised. The period of early and late atresia has been estimated as 3-4 days (Byskov 1974; Osman 1985; Greenwald, 1989). Butcher and Kirkpatrick-Keller (1984) described early atresia as a very rapid process. However, only Osman (1985) gave a more detailed description of timing of the atretic process. He suggested that early $1^{a}$ plus $1^{b}$ atresia, according to his definitions, would take at least $24 \mathrm{~h}$, and that at least another $24 \mathrm{~h}$ is needed for the $2^{\mathrm{a}}$ phase of atresia. The time that follicles persisted in the $2^{b}$ late atretic stage was not determined because there were no criteria for the end of this stage. One way of arriving at some answer to the question of the actual duration of early atresia is to study the effects of other time values for atresia on the model presented here.

A reasonable value for the duration of the stage of early atresia was found by multiplying the number of early atretic follicles by a certain factor to simulate other durations. For instance, when atresia takes $48 \mathrm{~h}$ and the sample rate is $24 \mathrm{~h}$, the same early atretic follicles are counted twice. This can be corrected for by multiplying the number of atretic follicles by 0.5 .

Models were calculated by multiplying the number of early atretic follicles by a value of $0.2,0.5,0.67,1.0,1.2$ and 1.5 to simulate a duration of the early atretic phase of $120,48,36,24$, 20 and $16 \mathrm{~h}$ (Table 2). Another group of rats killed at $17 \mathrm{~h}$ was included to reconfirm the results.

The longer times of atresia $(36-120 \mathrm{~h})$ resulted in four or more negative inflow numbers. A negative inflow means that follicles leave a healthy follicle class without reappearing in another healthy or atretic follicle class, i.e. extremely fast atresia, which contradicts the assumption of an early atretic period from 36 to $120 \mathrm{~h}$. Negative inflow numbers disappeared in the group of rats killed at $10 \mathrm{~h}$ when early atresia was assumed to take $24 \mathrm{~h}$ or less. In the rats killed at $17 \mathrm{~h}$, negative inflows disappeared when the assumed period of early atresia was $20 \mathrm{~h}$ or less. The negative inflow values were low from an early atretic period of $24 \mathrm{~h}$.

When the duration of early atresia decreases, the total number of follicles which enter follicle volume class 1 increases. When the number of follicles that disappear from the ovaries in one cycle is known, it is possible to determine the lower border of the duration of the stage of early atresia.

Pedersen (1970, 1972) calculated an inflow of 96 follicles per two ovaries into his follicle class $3^{\mathrm{b}}$ per 5 -day cycle in mice. This follicle class $3^{\mathrm{b}}$ consists of small preantral follicles with 20 or more granulosa cells (volume about $0.9 \times 10^{5} \mu \mathrm{m}^{3}$ ). The method used by Pedersen (thymidine pulse labelling) was completely different from the method used here. Using the same technique as Pedersen, Groen-Klevant (1981) found an inflow of 144 follicles per two ovaries per 5-day cycle in our rat strain. Butcher and Kirkpatrick-Keller (1984) mentioned an inflow of 21 follicles per ovary between pro-oestrus and oestrus in the rat which is almost the same number as in the model at an early atretic period of $24 \mathrm{~h}$ (23.6). Butcher and Kirkpatrick-Keller used histological examination of rat ovaries during the various days of the cycle. In a recent experiment we calculated the number of follicles in our rats that disappear from the ovary between day 40 and day 90 of life, by counting all follicles (preantral and antral healthy and early atretic) in each fifth serial section (Meijs-Roelofs et al., 1990). This number amounted to 115 follicles per two ovaries per 5-day cycle. Thus the number of follicles disappearing from the pool of healthy follicles every cycle may be between 115 and 144 in our rat strain. The period of early atresia could not be shorter than $20 \mathrm{~h}$ in the group of rats killed at $10 \mathrm{~h}$ in this study. If the stage of early atresia takes $20 \mathrm{~h}$, during young adult life, most of the follicles with a volume $\geq 100 \times 10^{5} \mu^{3}$ (volume class 1 ) would become atretic. Occurrence of atresia was found in follicles with volumes 
between 20 and $350 \times 10^{5} \mu^{3}$ (Mandl and Zuckerman 1952, 87-200 $\times 10^{5} \mu^{3}$; Pedersen, 1970, 1972, large follicles type $5^{\mathrm{b}}$ and $6 \pm 20-130 \times 10^{5} \mu^{3}$; Mariana and Meyer, 1979, $88 \%$ of atretic follicles $>149 \times 10^{5} \mu^{3}$; Butcher et al., 1984, $20-155 \times 10^{5} \mu^{3}$; Hirshfield, 1988, 41-350 $\left.\times 10^{5} \mu \mathrm{m}^{3}\right)$. The mentioned numbers of follicles lost per cycle (between 96, mice (Pedersen, 1970) and 144, rats (Groen-Klevant, 1981)) were all found in studies of young adult animals. When the animals were older the number of follicles that are lost per cycle will decrease (Meijs-Roelofs et al., 1990). These studies indicate that there is early atresia in follicles with a volume $<100 \times 10^{5} \mu \mathrm{m}^{3}$, but most atresia is found in the bigger antral follicles, so the stage of early atresia must take longer than $20 \mathrm{~h}$. Best results were obtained when the stage of early atresia takes between 20 and $24 \mathrm{~h}$.

In some cases in this study the number of follicles that leave a follicle class is bigger than the number of healthy follicles in this class. Some follicles did therefore grow more than the size of one class in $24 \mathrm{~h}$. This finding is to be expected because the volume classification was not intended to create classes in which healthy follicles would stay for $24 \mathrm{~h}$ or more.

The differences in the data from the groups of rats killed at 10 and $17 \mathrm{~h}$ are small and may be partly accounted for by the difference in timing. The difference in the total number of follicles entering follicle volume class 1 was about $12 \%$.

From the model presented here the following conclusions can be derived. First, the follicles that appear in volume class $I$ during pro-oestrus and oestrus seem to be the follicles that will ovulate at the next pro-oestrus. From these class 1 follicles, a selection is made that does not depend on their size during oestrus. At dioestrus 2 , the selected follicles can be pointed out as the larger follicles of the antral follicle pool (this study; see also Pedersen, 1970; Welschen, 1973; Butcher et al., 1984; Osman, 1985).

Second, follicles that ovulate at pro-oestrus seem to have developed according to the following time scheme: inflow into volume class 1 during pro-oestrus and oestrus, into volume class 2 during pro-oestrus and oestrus, into volume class 3 during oestrus and dioestrus 1 , into volume class 4 during dioestrus 1 and dioestrus 2 and finally, inflow into volume class 5 during dioestrus 2 and dioestrus 3 .

Third, in the total process of maturation and atresia during a cycle, about 120 follicles are lost (in agreement with Pedersen (1970), mice; Groen-Klevant (1981), rats; Meijs-Roelofs et al. (1990), rats).

Fourth, there is a continuous inflow of follicles into volume class 1 . However, this inflow is not constant: it is much higher during pro-oestrus and oestrus than during the dioestrous period. Probably there is a continuously, but slowly, growing pool of follicles that starts to grow much faster when influenced by the ovulatory FSH peak(s) (see also Welschen, 1973).
Among these follicles appear the 'privileged' ones destined to ovulate.

Finally, follicle selection seems to take place in the volume classes 1 and 2 during the days of oestrus and dioestrus 1 , since the follicles that eventually ovulate can be traced back to this period of the cycle.

In further studies, this model will be applied to describe the follicle dynamics in a situation of follicle stimulation with an FSH preparation. The model makes it possible to distinguish easily between reduced atresia and an increase in the follicle inflow and can also be used in other species, when numbers of healthy follicles and numbers of atretic follicles of certain stages are known.

The authors wish to thank J. Moll for critical reading of the manuscript.

\section{References}

Butcher RL and Kirkpatrick-Keller D (1984) Patterns of follicular growth during the four-day estrous cycle of the rat Biology of Reproduction 31 280-286

Byskov AGS (1974) Cell kinetic studies of follicular atresia in the mouse ovary Joumal of Reproduction and Fertility $37277-285$

Greenwald GS (1973) Distribution between developing reserve follicles in the cycling hamster Annales de Biologie Animale Biochimie Biophysique 13 199-210

Greenwald GS (1974) Quantitative aspects of follicular development in the untreated and PMS-treated cyclic hamster Anatomical Record 178 139-143

Greenwald GS (1989) Temporal and topographic changes in DNA synthesis after induced follicular atresia Biology of Reproduction 41 175-181

Groen-Klevant AC (1981) An autoradiographic study of follicle growth in the ovaries of cyclic rats Acta Endocrinologica 96 377-381

Hirshfield AN (1988) Size-frequency analysis of atresia in cycling rats Biology of Reproduction 38 1181-1188

Hirshfield AN (1989) Rescue of atretic follicles in vitro and in vivo Biology of Reproduction 40 181-190

Hirshfield AN and DePaolo LV (1981) Effect of suppression of the surge of follicle stimulating hormone with porcine follicular fluid on follicular development in the rat Joumal of Endocrinology 88 67-71

Mandl AM and Zuckerman S (1952) Cyclical changes in the number of medium and large follicles in the adult rat ovary Journal of Endocrinology $8341-346$

Mariana JC and Meyer JA (1979) Application of a simulation method for the study of beginning growth in ovarian follicles Annales de Biologie Animale Biochimie Biophysique 19 1435-1442

Meijs-Roelofs HMA, van Cappellen WA, van Leeuwen ECM and Kramer P (1990) Short-term and long-term effects of an LHRH antagonist given during the prepubertal period on follicle dynamics in the rat Joumal of Endocrinology 124 247-253

Osman P (1985) Rate and course of atresia during follicular development in the adult cyclic rat Journal of Reproduction and Fertility 73 26I-270

Pedersen T (1970) Follicle kinetics in the ovary of the cyclic mouse Acta Endocrinologica 64 304-323

Pedersen T (1972) Follicle growth in the mouse ovary. In Oogenesis pp 261276 Eds JD Biggers and AW Schutz. University Park Press, Baltimore. Butterworth, London

Peters H and Levy E (1966) Cell dynamics of the ovarian cycle Journal of Reproduction and Fertility 11 227-236

Welschen R (1973) Amounts of gonadotrophins required for normal follicular growth in hypophysectomized adult rats Acta Endocrinologica 72 137-155 